Article

\title{
Surveillance of Host-Seeking Ticks in the Flint Hills Region (USA) and Associations with Environmental Determinants
}

\author{
Mark Spare ${ }^{1}$, Gunavanthi D. Boorgula ${ }^{2}$, Dan Thomson ${ }^{3}$, Jianfa Bai ${ }^{4}$, , Doug Goodin ${ }^{5}$, Gary Anderson ${ }^{6}$, \\ Roger W. Stich ${ }^{7}$, Ali Hroobi ${ }^{8}$ (), Savannah Wilson ${ }^{4}$, Alexander Staggs ${ }^{4}$, Ashley Bowers ${ }^{4}$, Alexandra Hamm ${ }^{4}$, \\ Jayden Tatman ${ }^{4}$ and Ram K. Raghavan ${ }^{7,9, *}$ (i)
}

check for

updates

Citation: Spare, M.; Boorgula, G.D.;

Thomson, D.; Bai, J.; Goodin, D.;

Anderson, G.; Stich, R.W.; Hroobi, A.;

Wilson, S.; Staggs, A.; et al.

Surveillance of Host-Seeking Ticks in

the Flint Hills Region (USA) and

Associations with Environmental

Determinants. Parasitologia 2021, 1,

137-147. https://doi.org/10.3390/

parasitologia1030015

Academic Editors: Annetta Zintl and Geoff Hide

Received: 7 May 2021

Accepted: 4 August 2021

Published: 7 August 2021

Publisher's Note: MDPI stays neutral with regard to jurisdictional claims in published maps and institutional affiliations.

Copyright: (c) 2021 by the authors. Licensee MDPI, Basel, Switzerland. This article is an open access article distributed under the terms and conditions of the Creative Commons Attribution (CC BY) license (https:// creativecommons.org/licenses/by/ $4.0 /)$.
1 MKS Cattle Company, 620 Northfield Rd., Manhattan, KS 66502, USA; mspare25@vet.k-state.edu

2 Center for Biomedical Research, Department of Pulmonary Immunology, The University of Texas Health Science Center, Tyler, TX 75708, USA; gunavanthidevi.boorgula@uthct.edu

3 Department of Animal Science, College of Agriculture and Life Science, Iowa State University, Ames, IA 50011, USA; thomson1@iastate.edu

4 Department of Diagnostic Medicine and Pathobiology, College of Veterinary Medicine, Kansas State University, Manhattan, KS 66506, USA; jbai@vet.k-state.edu (J.B.); savannahleigh@ksu.edu (S.W.); alex81@ksu.edu (A.S.); ambowers@ksu.edu (A.B.); alexrh94@ksu.edu (A.H.); jtatman@ksu.edu (J.T.)

5 Department of Geography, College of Arts and Sciences, Kansas State University, Manhattan, KS 66506, USA; dgoodin@ksu.edu

6 Medgene Labs, Paola, KS 66071, USA; ganders@vet.k-state.edu

7 Department of Veterinary Pathobiology, College of Veterinary Medicine, University of Missouri, Columbia, MO 65211, USA; roger.w.stich@missouri.edu

8 Department of Biology, College of Science, Al-Baha University, Al-Baha 65779-77388, Saudi Arabia; alihroobi77@gmail.com

9 Department of Public Health, School of Health Professions, University of Missouri, Columbia, MO 65211, USA

* Correspondence: RaghavanRK@missouri.edu

Abstract: Diversity and phenology of host-seeking ticks were studied in the Flint Hills region of the USA, which is a prominent region for raising beef cattle. Between a two-year period from 2015-2017, ticks were collected using the dragging method from 9 distant locations, 6 of which were studied seasonally and 3 continuously throughout the study period. Of the 10,055 ticks collected, $76.5 \%$ were the Lonestar tick (Amblyomma americanum), 14\% were American dog tick (Dermacentor variabilis), and 9.1\% were Gulf Coast tick (A. maculatum). The blacklegged tick, Ixodes scapularis were also found, albeit in low numbers. The host-seeking activity of all three predominant tick species peaked once during the late spring, summer months in the region. The phenology of all ticks was positively associated with accumulated temperature and photoperiod. Additionally, the Normalized Vegetation Difference Index (NDVI) was associated with A. americanum, and saturation deficit and relative humidity were negatively associated with $D$. variabilis and A. maculatum tick phenology, respectively. This finding is useful to predict the times during a year in which cattle are at higher risk for exposure to these ticks and associated pathogens.

Keywords: tick; Amblyomma americanum; Amblyomma maculatum; Dermacentor variabilis; Ixodes scapularis; Flint Hills; NDVI; saturation deficit; accumulated temperature; photoperiod

\section{Introduction}

Ticks are medically- and economically important hematophagous pests that affect livestock production worldwide. Estimated losses due to bovine anaplasmosis alone, which is caused by a rickettsia pathogen that is biologically transmitted by ticks ranges in the several millions of dollars every year in the US. For instance, previous estimates of the cost of a clinical bovine case due to anaplasmosis was estimated to be around $\$ 400$ /animal [1,2], and in 1996 the total economic impact was conservatively estimated to be around $\$ 300$ million/year in the U.S. alone [3]. Losses due to other tick-borne diseases 
to livestock and companion animals are not readily available but can be reliably expected to be in several hundreds of millions each year. Tick-borne diseases of humans and animals in the midwestern U.S. have reportedly increased in their frequency and intensity over recent years [4-10], and particularly the spatiotemporal pattern of bovine anaplasmosis in the midwestern U.S. has steadily worsened over the past decade [8].

The Flint Hills ecoregion in the Midwestern US, mostly in eastern Kansas but also in northcentral Oklahoma represents an important area for livestock production in the U.S. Poorly suited for cultivation and crop production, this area is recognized for its superior grass quality which leads to higher grazing performance by cattle. Due to the seasonality and relatively better grass quality in the Flint Hills, millions of cattle are brought to pastures from other parts of the US, which include young growing cattle (stockers) and reproductive females (i.e., cowherds), adding diversity to the complexity of the grazing population. Ticks, including Dermacentor variabilis, that is implicated in the transmission of Anaplasma marginale, the etiologic agent of bovine anaplasmosis, are commonly found in the broader region. Thus, the exposure of recently introduced naïve cattle to ticks infected by feeding on indigenous vertebrate carriers is a concern.

The present study evaluates the diversity of different questing tick species and their phenology in Flint Hills ecoregion by conducting tick surveys at 9 locations over a two-year period between 2015-2017. Tick distribution over space and time are predictable with environmental variables [11-13]. The associations of such weather conditions with tick density were evaluated using ground-level and remotely sensed data. The information generated in this study is expected to contribute to our understanding of reasons behind the current increase in bovine anaplasmosis cases in this region [8]. Thus, for improving the management of this economically important disease. Additionally, the data generated in this study will serve as a baseline for future investigations of tick diversity and phenology aimed to measure the dynamics of tick populations in this ecoregion, including those associated with ongoing biotic and abiotic (e.g., climate-change) changes in this environment.

\section{Results}

During the two-year study period from 2015-2017, a total of 10,557 ticks were collected from 9 collection sites in the Flint Hills ecoregion; 8083 (76.5\%) of these ticks were identified as Amblyomma americanum; $1,481(14.0 \%)$ as D. variabilis; $965(9.14 \%)$ as A. maculatum; and $28(0.26 \%)$ as Ixodes scapularis. The male/female ratio for all four species did not change during in the two years that ticks were collected, and in general, there were more females relative to males for all species in both years. The sex ratio for A. americanum was 0.61:1 (male: female), for $D$. variabilis, 0.69:1, and for A. maculatum, 0.78:1. The sex ratio for I. scapularis could not be reliably estimated due to the low number of samples collected. All developmental stages of $A$. americanum and adult stage $D$. variabilis were collected from all sampling sites, whereas $A$. maculatum were not collected from study sites located north of Manhattan, Kansas. Ixodes scapularis was collected only from two study sites in the southern part of the study region.

Among A. americanum ticks, larvae (33.13\%) and nymphs (33.55\%), all identified using PCR in pools of 10 larvae or 10 nymphs, contributed to a large portion of the collection, followed by female (20.64\%) and male (12.66\%) adults. Larvae and nymphs of $D$. variabilis and A. maculatum were not detected in the PCR analysis, i.e., not collected by flagging; the proportion of male and female ticks of these species were $(41 \%$ and $59 \%$, and $44 \%$, $56 \%$, respectively.

To determine the phenology of these ticks, a total of 4557 ticks were collected from the three long-term sites that were sampled each month throughout the study period. The specimens collected from these sites included, $A$. americanum males $(\mathrm{n}=319)$, females $(\mathrm{n}=523)$, nymphae $(\mathrm{n}=807)$ and larvae $(\mathrm{n}=969)$. D. variabilis males $(\mathrm{n}=191)$ and females $(\mathrm{n}=275)$; and $A$. maculatum males $(\mathrm{n}=63)$ and females $(\mathrm{n}=100)$ (Table 1$)$. All the above three species of ticks were present in the three long-term sites. Regardless of the collection site, the three major tick species found in the Flint Hills ecoregion displayed a unimodal 
density distribution in both years (Figure 1). Noticeable overlap in the emergence of the three post-emergent life-stages of $A$. americanum ticks was evident but the nymphs emerged relatively earlier in the season followed by adults and larvae. In both years, the peak activity of A. americanum nymphs occurred in May, adults peaked in June and then larvae in August. Adult density of $D$. variabilis increased in July and the emergence of $A$. maculatum adults occurred earliest in the year among the three metastriate species, in May.

Table 1. Tick stages collected from Flint Hills ecoregion (USA) over a two-year study period March 2015-March 2017.

\begin{tabular}{ccccccc}
\hline Species & Year & Male & Female & Nymph & Larvae & Total \\
\hline Amblyomma & Year 1 & 518 & 782 & 1265 & 1309 & 3874 \\
americanum & Year 2 & 506 & 887 & 1447 & 1369 & 4209 \\
\hline Amblyomma & Year 1 & 222 & 269 & - & - & 491 \\
maculatum & Year 2 & 203 & 271 & - & - & 474 \\
\hline Dermacentor & Year 1 & 321 & 450 & - & - & 771 \\
variabilis & Year 2 & 286 & 424 & - & - & 710 \\
\hline Ixodes & Year 1 & 2 & 6 & - & - & 8 \\
scapularis & Year 2 & 5 & 15 & - & - & 20 \\
\hline
\end{tabular}

The final generalized linear mixed models (glmm) for each species evaluated climate associations with tick density revealing that accumulated temperature and photoperiod were significantly associated with all three tick species collected from the Flint Hills ecoregion between 2015-2017 (Tables 2-4). The normalized difference vegetation index (NDVI) was associated with the density of A. americanum ticks while saturation deficit, a measure of drying power of the air was significantly but negatively associated with $D$. variabilis (Table 4), and maximum relative humidity was negatively associated with A. maculatum ticks (Table 5). The random effect parameters, month of collection and location were significant in all glmm models.

Table 2. Associations of climate and land cover properties with density of Amblyomma americanum ticks (larva, nymph and adult together) fitted in a generalized linear mixed model (glmm).

\begin{tabular}{ccccc}
\hline Covariate & Estimate & Std. Error & $\operatorname{Pr}(>|\mathrm{z}|)$ & $\mathbf{9 5 \%}$ CI \\
\hline Accumulated & 1.232 & 0.012 & 0.000 & $1.209,1.256$ \\
temperature & 1.079 & 0.031 & 0.000 & $1.019,1.140$ \\
Photoperiod & 0.121 & 0.010 & 0.017 & $0.101,0.1406$ \\
NDVI & 1.553 & 0.496 & 0.015 & $0.580,2.525$ \\
Location & 0.811 & 0.213 & 0.007 & $0.039,1.228$ \\
Month & & & & \\
\hline
\end{tabular}

Table 3. Associations of climate variables with density of adult Dermacentor variabilis ticks fitted in a generalized linear mixed model (glmm).

\begin{tabular}{ccccc}
\hline Covariate & Estimate & Std. Error & $\operatorname{Pr}(>|\mathbf{z}|)$ & $\mathbf{9 5 \% ~ C I ~}$ \\
\hline Accumulated & 1.421 & 0.119 & 0.000 & $1.877,1.654$ \\
temperature & 1.549 & 0.088 & 0.001 & $1.376,1.721$ \\
Photoperiod & -1.388 & 0.192 & 0.038 & $-1.764,-1.011$ \\
Saturation & 1.321 & 0.622 & 0.048 & $0.101,2.540$ \\
deficit & 0.422 & 0.183 & 0.001 & $0.063,0.780$ \\
Location & & & & \\
Month & & &
\end{tabular}



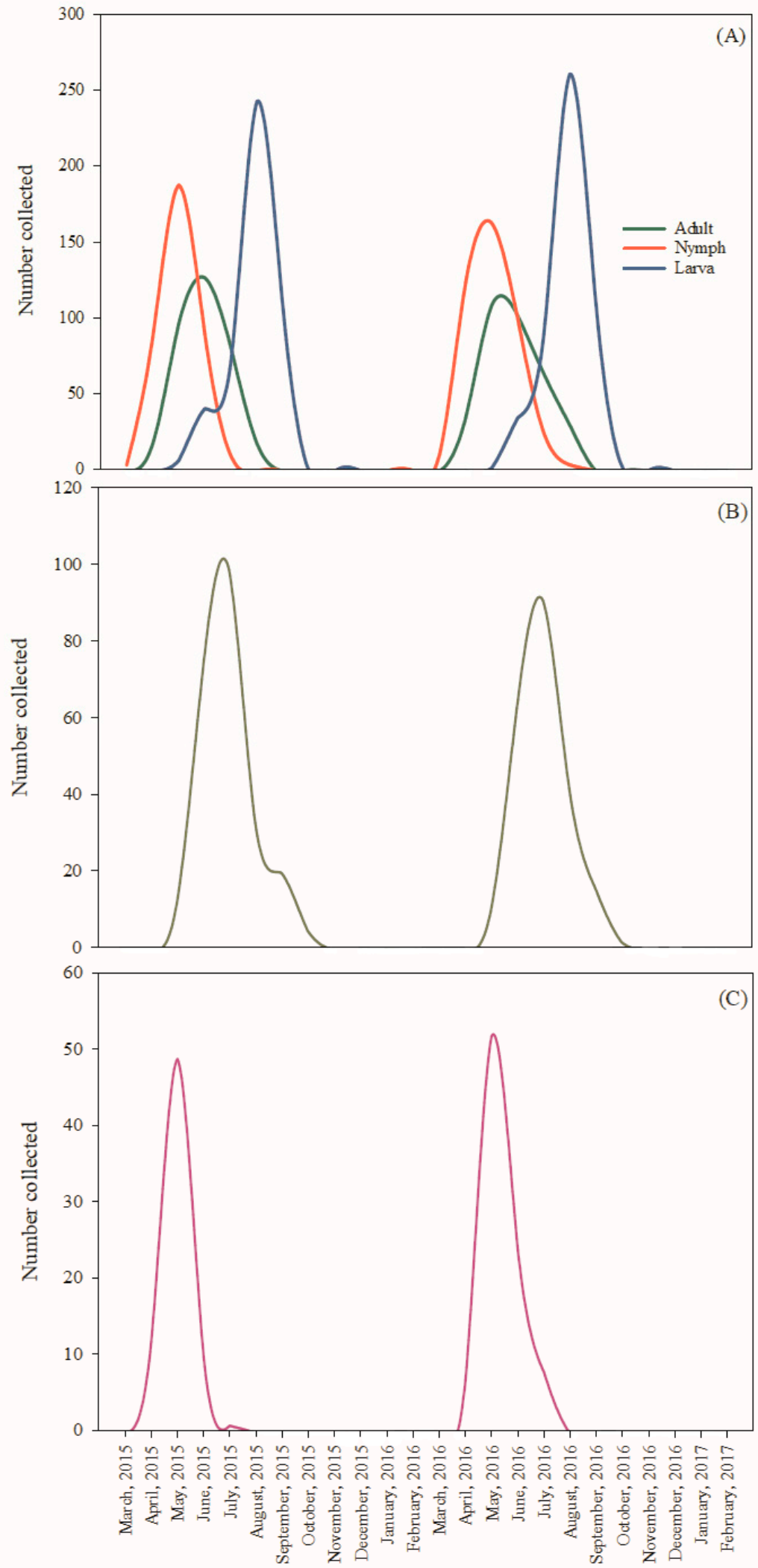

Figure 1. Total numbers of ticks collected every month from sampling locations in Flint Hills ecoregion (USA). (A) Amblyomma americanum adult, nymphae and larvae; (B) Dermacentor variabilis adults; (C) Amblyomma maculatum adults. 
Table 4. Associations of climate variables with density of adult Amblyomma maculatum ticks fitted in a generalized linear mixed model (glmm).

\begin{tabular}{ccccc}
\hline Covariate & Estimate & Std. Error & $\operatorname{Pr}(>|\mathrm{z}|)$ & $\mathbf{9 5 \%}$ CI \\
\hline Accumulated & 2.076 & 0.083 & 0.000 & $1.913,2.238$ \\
temperature & 0.373 & 0.108 & 0.000 & $0.165,0.588$ \\
$\begin{array}{c}\text { Photoperiod } \\
\text { Mean relative }\end{array}$ & -0.274 & 0.187 & 0.041 & $-0.640,0.092$ \\
humidity & 1.118 & 0.288 & 0.038 & $0.553,1.682$ \\
Location & 1.027 & 0.261 & 0.001 & $0.514,1.538$ \\
Month & & & & \\
\hline
\end{tabular}

\section{Discussion}

The objective of this study was to evaluate the diversity and phenology of questing ticks in an area where livestock production is a major economic driver, and to quantify the presence of and strength of associations between tick density and abiotic environmental drivers. To the collective knowledge of the authors, intensive tick surveys to investigate the diversity or phenology of ticks has not been conducted in the Flint Hills region in recent decades. The findings reported here therefore provide a fresh insight into the tick ecology in this region, which will be useful for designing management practices to counter the spread of bovine anaplasmosis and other tick-borne diseases. One such management practice could be the potential adjustment of the timing and/or method of burning seasonal grasses, a practice that is routinely followed by cattle ranchers in the region. Patch burning has been evaluated as a method to reduce tick burden in intensive cattle grazing areas [14,15]. These studies report a significant reduction in the number of cattle-attached ticks following patch burning and a subsequent reduction in tick-borne diseases.

The distinctive and consistent unimodal phenology of questing adults of all three tick species and the immature stages of $A$. americanum, for both years indicate that there is currently a single season during which these ticks are actively questing for bloodmeal hosts in the Flint Hills. These patterns were similar to those previously reported for A. americanum collected from pastured beef cattle, with overwintered adult and nymph stages appearing in the spring followed by larvae in late summer and autumn [16]. Interestingly, although it was reported that $A$. americanum nymphs and adults began questing in the Cookson Hills State Game Refuge (CHSGR) in eastern Oklahoma as early as late winter in 1973 and 1974, fed stages of these ticks were not found, in the same study, on white-tailed deer until late spring/early summer $[16,17]$. Thus, further work is warranted to determine if a similar phenomenon currently occurs in the Flint Hills, which are northwest of the CHSGR.

Too few I. scapularis ticks were collected in this study to make robust conclusions, but the adults of this species were all collected during late fall, indicating a cool-season peak for the adults and potentially its immature life-stages. Previous studies of I. scapularis ticks from the region indicate a similar activity period [18-20]. Tick density for the other three species appears to increase as temperatures warm-up in early spring and last until early fall; however, the peak activity for these species (and for the different life stages of A. americanum) occurred at different times during this roughly 6-month period, often within a narrow one- or two-month timeframe.

Accumulated temperature and photoperiod are reliable predictors of tick density in the Flint Hills, a finding similar to that reported in a recent study by Remesar et al., 2019 on Ixodes ricinus ticks in Spain [21]. Ticks are poikilothermic arthropods whose survival and fitness are closely linked to ambient conditions. Temperature and moisture available in the atmosphere, represented either as relative humidity or saturation deficit, have been long shown to exert significant effect on the questing behavior [22,23], development rate [24-27] and reproduction and survival $[28,29]$ of various ixodid ticks, and they are a major limiting factor of the geographic distribution of a tick species [30-32]. NDVI, an index for remotely detecting photosynthetic activity of plants is associated with A. americanum density in the 
present study. NDVI has been shown to correlate with the life history traits of different ticks and has been widely discussed as a reliable predictor of tick phenology in many cases [33]. The phenology of other ticks found in the Flint Hills, however, appears not to be predictable when using NDVI, as is the case with some of the other Ixodidae [21].

The density of adult $D$. variabilis ticks increased as the saturation deficit increased, indicating that the emergence and questing behavior of the adults of these ticks coincided with drier conditions in the Flint Hills. However, it is important to consider the effect of saturation deficit not in isolation but in the presence of accumulated temperature and photoperiod as these covariates together contributed to the mixed model (Table 3). The effect of photoperiod on $D$. variabilis has been shown to affect the questing behavior $[26,34]$, with longer photoperiods increasing questing activity. Similarly, the maximum relative humidity recorded per month is associated with the density of A. maculatum ticks, with lower relative humidity favoring increased density.

All questing tick species collected in this study have been implicated in the transmission of pathogenic agents to humans and animals and these species are therefore intensely researched. Apart from the well-known pathogens transmitted by A. americanum (see: Childs and Paddock, 2002) [35], the nymphs of these ticks were recently confirmed as transmitting agents of Heartland virus (HRTV) [9,36] and Bourbon virus (BRBV) [10], which, such as rickettsial agents transmitted by these species, have been responsible for human fatalities. The intensity and frequency of other diseases transmitted by A. americanum have been steadily worsening over the recent years $[5,7,8,37]$, and recently it was shown via ecological niche modeling that the potential geographic distribution of this species is broader in N. America than what was previously thought [30].

Anaplasmosis disease burden to cattle that are raised in the Flint Hills region are not accurately estimated; however, it is commonly accepted that the economic losses due to this disease are severe. It is likely that much of the reason for the prevalence of this disease in this economically vital region is caused by a combination of factors; accidental mechanical transmission of $A$. marginale during routine care of cattle and vertical transmission of the pathogen from cows to calves being some among them. American dog ticks (D. variabilis) have been implicated as an important biologic vector of $A$. marginale, but they are clearly not the dominant tick species in this region, accounting only $14 \%$ of the total host-seeking ticks collected in the present study. It must be noted that the immature stages of $D$. variabilis ticks in contrast with the other common ticks in this region are seldom collected using cloth drags as their questing behavior is different and closer to ground. Nevertheless, D. variabilis have been reported in association with cattle in nature [38,39], and this tick has been repeatedly demonstrated capable of acquisition, maintenance and transmission of $A$. marginale [40-42]. Thus, the relatively less abundant $D$. variabilis ticks play an important role as biologic vectors from subclinical carriers to naïve cattle, and possible as invertebrate maintenance and reservoir hosts of $A$. marginale during the interannual periods such that a continuous infection to naïve herds is possible [42]. The infection rate of this pathogen among D. variabilis ticks in Flint Hills is not presently known, and such information is warranted for evaluating the role of these ticks in the maintenance and spread of $A$. marginale.

\section{Materials and Methods}

\subsection{Study Area}

This study was conducted in the Flint Hills, a narrow north-to-south region located in eastern Kansas and northcentral Oklahoma, designated by the US Environmental Protection Agency as an ecoregion characterized by dense coverage of different tallgrass species. Flint Hills landscape is mainly composed of prairie vegetation dominated by big and little bluestem, switch grass and Indian grass. Trees are seldom found, except along stream and river bottoms where they are abundant creating areas of forest-field interface. Flint Hills ecoregion covers an area of $25,333 \mathrm{~km}^{2}$ with wide interannually varying continental climate. Climate conditions here range from extreme heat in summer with highs ranging between 
$26-43{ }^{\circ} \mathrm{C}$, to lows in the winter dropping to $-29^{\circ} \mathrm{C}$. Precipitation varies highly from year to year with average precipitation received in the area being approximately $84 \mathrm{~cm}$.

\subsection{Tick Survey and Classification}

For the evaluation of tick diversity, questing ticks were collected from 12 locations (Figure 2) between the months of March through August using a $1 \mathrm{~m}^{2}$ white flannel cloth attached to a $1.3 \mathrm{~m}$ long flagpole for a fixed amount of time $(1 \mathrm{~h})$. Ticks attached to the flannel were collected every 2-5 $\mathrm{m}$ using forceps and stored in a plastic container until they were brought to the laboratory and placed on dry ice. Tick surveys were performed by six similarly trained biologists during the entire study period, but these tick collectors were changed once in the second year of the study.

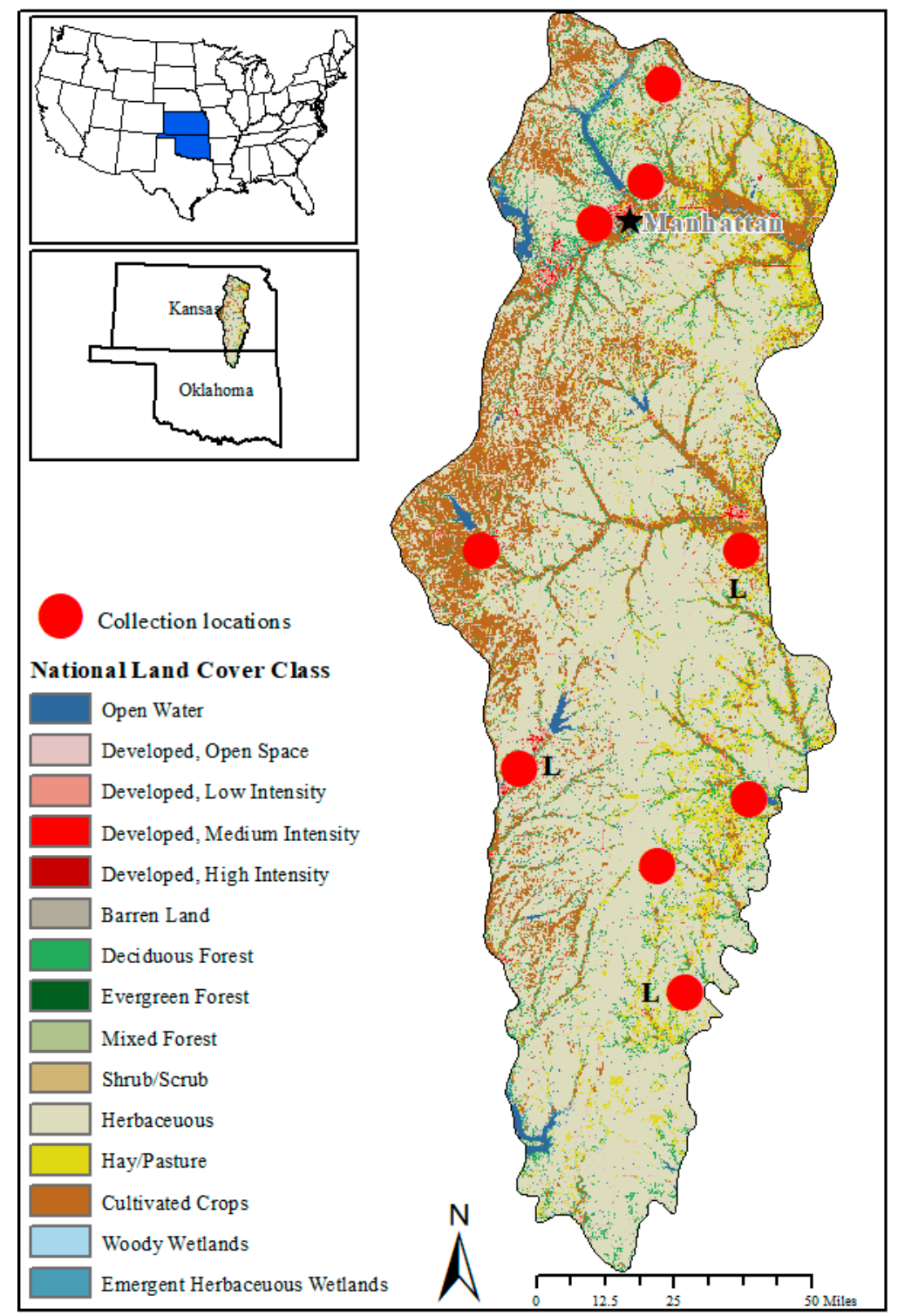

Figure 2. Tick sampling sites and Flint Hills ecoregion (USA). Long-term sites are denoted by L.

To study the phenology of ticks, three sites were selected, in the north, central and southern Flint Hills ecoregion to represent any potential climate variation. From these sites, ticks were collected from $300 \mathrm{~m}^{2}$ transects, once a month from the beginning of March 2015 through end of March 2017, as described above, except for periods when the transects were under snow cover and/or the temperature was below freezing. No time limit was set and entire transects were swept for ticks over the vegetation cover. Once in the lab, ticks were 
placed in $-20^{\circ} \mathrm{C}$ for $48-56$ hours after which time they were thawed and microscopically identified to their species level using N. American tick taxonomic keys [43]. Nymphs and larvae were first identified using morphological keys, and to further confirm the species, a subset of these ticks was evaluated using molecular analysis with the PCR technique.

\subsection{Sample Handling and DNA Extraction}

Ticks were first thawed to room temperature and identified using morphologic characteristics. For the larvae and nymphs that were not identifiable with taxonomic keys, pools of 10 larvae per pool and 10 nymphs per pool were individually prepared. Total genomic DNA from these pools were extracted using the QIAGEN DNeasy Blood and Tissue kit (QIAGEN, Valencia, CA, USA) following the recommended manufacturer's protocol with the following exceptions. The tube contents were homogenized in $2 \mathrm{ml}$ Lysing Matrix M screw-capped tubes filled with $\frac{1}{4}$ " $(6.35 \mathrm{~mm})$ diameter of Zirconium Oxide ceramic grinding spheres (MP biomedicals. LLC), and $180 \mu \mathrm{L}$ of ATL buffer (QIAGEN, Valencia, CA, USA), $25 \mu \mathrm{L}$ of proteinase $\mathrm{K}$ (QAIGEN, Valencia, CA, USA). These tubes were incubated at $56^{\circ} \mathrm{C}$ with shaking for $1 \mathrm{~h}$ in a Disruptor Genie cell disruptor (Scientific Industries, Inc, Bohemia, NY, USA), and subsequently treated according to the kit instructions. DNA concentrations were measured with NanoDrop spectrophotometer (ThermoFisher, Wilmington, DE, USA) and stored at $-20^{\circ} \mathrm{C}$ until used for PCR-based detection of gDNA.

\subsubsection{Positive Control Construction}

Positive amplification controls including those for A. americanum, A. maculatum and D. variabilis were synthesized and cloned into a plasmid vector.

\subsubsection{Real-Time PCR}

Oligonucleotides used for PCR are listed in Table 5 and were prepared at $10 \mathrm{pMol} / \mu \mathrm{L}$. The singular real-time PCR assays were conducted with a Bio-Rad CFX96 Real-time PCR detection system with the iQ Multiplex Powermix kit (BioRad, Hercules, CA, USA). For each PCR, a $20 \mu \mathrm{L}$ reaction was prepared, which contained $10 \mu \mathrm{L} 2 \mathrm{X}$ IQ Powermix, $5 \mu \mathrm{L}$ DNA template, $1 \mu \mathrm{L}$ probe, $1 \mu \mathrm{L}$ of each primer and $2 \mu \mathrm{L}$ nuclease free water. An initial denaturation at $95{ }^{\circ} \mathrm{C}$ for $10 \mathrm{~min}$ was followed by 45 cycles of $95{ }^{\circ} \mathrm{C}$ for $15 \mathrm{sec}$, the annealing and extension temperature at $65{ }^{\circ} \mathrm{C}$ for $45 \mathrm{~s}$. The end results are analyzed using Bio-Rad CFX Manager 3.0 software. Annealing temperatures for individual PCR assays were first optimized using temperature gradient PCR (Bio-Rad CFX96). The optimal annealing temperatures of the assay were determined based on signal intensities of the PCR amplifications. Ct value $\leq 30$ were considered strongly positive reactions obtained by abundant target nucleic acids in the samples. Selected amplification products were verified by electrophoresis on $1.5 \%$ agarose. The expected amplicon sizes for the respective tick species are described in Table 5

Table 5. Oligonucleotide primers and probes used in real-time PCR assays.

\begin{tabular}{|c|c|c|c|c|}
\hline Species & Target Gene & Product Size & Primes /Probes & $\begin{array}{l}\text { Sequence } \\
\left(5^{\prime}-3^{\prime}\right)\end{array}$ \\
\hline $\begin{array}{l}\text { Amblyomma } \\
\text { americanum }\end{array}$ & 16S rRNA & $150 \mathrm{bp}$ & $\begin{array}{l}{ }^{*} \mathrm{FP} \\
{ }^{*} \mathrm{RP} \\
{ }^{*} \mathrm{Pr}\end{array}$ & $\begin{array}{c}\text { TTTAATTGGGGCGATTTAACTA } \\
\text { CATCGAGGTCGCAAACTATT } \\
\text { FAM-GAACCGTTATTAACGGACACTTGGA-BHQ-1 }\end{array}$ \\
\hline $\begin{array}{l}\text { Amblyomma } \\
\text { maculatum }\end{array}$ & 16S rRNA & $178 b p$ & $\begin{array}{l}{ }^{*} \mathrm{FP} \\
{ }^{*} \mathrm{RP} \\
{ }^{*} \mathrm{Pr}\end{array}$ & $\begin{array}{c}\text { AAGGACAAGAAGACCCTAAGAATTT } \\
\text { ATTACGCTGTTATCCCTAGAGTATTT } \\
\text { CAL Fluor Red } \\
\text { 610-TGAAATTTTTTAATTGGGGCGA-BHQ-2 }\end{array}$ \\
\hline $\begin{array}{c}\text { Dermacentor } \\
\text { variabilis }\end{array}$ & 16S rRNA & $138 \mathrm{bp}$ & $\begin{array}{l}{ }^{*} \mathrm{FP} \\
{ }^{*} \mathrm{RP} \\
{ }^{*} \mathrm{Pr}\end{array}$ & $\begin{array}{c}\text { TGGTATTTTGACTATACAAAGGTATT } \\
\text { CCTTAATTTTAATAATTGTTTCTTCAC } \\
\text { CAL Fluor Gold 540- } \\
\text { TGCTAAGAGAATGGAATTACAGGGAATA-BHQ-1 }\end{array}$ \\
\hline
\end{tabular}

* FP: Forward primer; RP: Reverse primer; Pr: Probe. 


\subsection{Environmental Data}

Climate and landcover properties affect tick biology [44]. Daily climate data for the study period, closest to the sampling locations were obtained from the National Weather Service (NWS) and cooperative stations. This data included temperature (minimum, maximum and mean), relative humidity, precipitation and wind speed. Daily evapotranspiration and soil moisture index were derived from the raw climate records. Vegetation index data for this analysis was extracted from the MOD13A2 product derived from the MODIS instrument onboard the EOS-Terra platform. Vegetation indices from this product (NDVI, EVI) are calculated from the blue, red and near infrared MODIS bands using daily atmosphere-corrected bidirectional reflectance values over 16-day compositing periods. Composite index values for the 16-day periods are selected to represent each compositing period by culling all pixels whose quality assurance metrics fall below a minimum standard, then selecting the highest index value from the view angle that is closest to nadir. The study site was located on the H10V05 MODIS tile.

\subsection{Statistical Analysis}

The association between climate and land cover covariates with tick density for each species was evaluated in a Generalized Linear Mixed Model construct using the glmm package (see Knudson, 2018) [45] in R-Statistical program [46]. The correlation among covariates were first assessed and pairs of covariates with $R$ value $>8$ were removed. Model over-fitting can lead to finding erroneous associations. Therefore, before fitting the glmm model, the strength of associations between tick density and different fixed-effect covariates were individually screened by fitting univariate models with a liberal cut-off $P$-value. Only those fixed-effect covariates that retained statistical significance $(p \leq 0.1)$ were kept for the glmm model; in which, log normalized tick density was the dependent variable, different climate and land cover covariates were fixed-effect independent variables, and location, month and year of tick collection were kept as random-effect variables. A full model with all screened variables and random effects was fitted first, followed by several mixed models with fewer fixed-effect covariates at each step without those that were non-significant $(p \leq 0.05)$. These steps were followed independently for each tick species.

\section{Conclusions}

This study evaluated the diversity of different questing tick species and their phenology in the Flint Hills ecoregion and the authors describe the presence of three major tick species having similar density distribution with overlap in emergence. Specifically, the increase in adult density of $D$. variabilis in late July will be a helpful guide for understanding regional and within-herd risk for transmission of $A$. marginale, the primary etiologic agent of bovine anaplasmosis. The information described in this study also provides a foundation for future studies on the monitoring of tick population dynamics in this important ecoregion of the Midwest. Further research is warranted in the year-to-year variation in the emergence of the tick as well as the ability of the ticks within a region to harbor the disease agents without continued reinfection from reservoir cattle.

Author Contributions: Conceptualization, R.K.R. and D.T.; methodology, R.K.R., M.S., G.D.B. and D.G.; software, R.K.R. and D.G.; validation, M.S., G.D.B. and J.B.; formal analysis, M.S., J.B., R.K.R. and D.G.; investigation, M.S., A.H. (Alexandra Hamm), A.S., S.W., A.B., A.H. (Ali Hroobi) and J.T.; resources, G.A. and D.T.; data curation, M.S., G.D.B., D.G., A.H. (Alexandra Hamm), A.B., A.H. (Ali Hroobi), J.T., S.W. and A.S.; writing-original draft preparation, M.S., R.K.R., G.D.B., J.B., D.T. and D.G.; writing-review and editing, R.K.R., M.S., D.T., J.B., G.A. and R.W.S.; supervision, R.K.R., M.S. and J.B.; project administration, R.K.R. and D.T.; funding acquisition, D.T., G.A. and R.K.R. All authors have read and agreed to the published version of the manuscript.

Funding: This research received no external funding.

Institutional Review Board Statement: Not applicable.

Informed Consent Statement: Not applicable. 
Data Availability Statement: Data presented in the study may be requested for reasonable research use from the corresponding author, and may require institutional approval for release.

Acknowledgments: The authors are grateful to Elizabeth Porter and Nanyan Yu, Kansas State University for their help with molecular analysis.

Conflicts of Interest: The authors declare no conflict of interest.

\section{References}

1. Goodger, W.J.; Carpenter, T.; Riemann, H. Estimation of economic loss associated with anaplasmosis in California beef cattle. J. Am. Vet. Med. Assoc. 1979, 174, 1333-1336.

2. Alderink, F.J.; Dietrich, R.A. Economic and Epidemiological Implications of Anaplasmosis in Texas Beef Cattle Herds. Available online: https: / / core.ac.uk/download/pdf/18488711.pdf (accessed on 6 August 2021).

3. Okafor, C.C.; Collins, S.L.; Daniel, J.A.; Harvey, B.; Coetzee, J.; Whitlock, B. Factors associated with seroprevalence of bovine anaplasmosis in Texas. Vet. Parasitol. Reg. Stud. Rep. 2018, 14, 32-40. [CrossRef] [PubMed]

4. Raghavan, R.K.; Harrington, J.; Anderson, G.A.; Hutchinson, J.S.; Debey, B.M. Environmental, climatic, and residential neighborhood determinants of feline tularemia. Vector Borne Zoonotic Dis. 2013, 13, 449-456. [CrossRef]

5. Raghavan, R.K.; Neises, D.; Goodin, U.G.; Andresen, D.A.; Ganta, R.R. Bayesian spatio-temporal analysis and geospatial risk factors of human monocytic ehrlichiosis. PLoS ONE 2014, 9, e100850. [CrossRef]

6. Raghavan, R.K.; Almes, K.; Goodin, D.G.; Harrington, J.A., Jr.; Stackhouse, P.W., Jr. Spatially heterogeneous land cover/land use and climatic risk factors of tick-borne feline cytauxzoonosis. Vector Borne Zoonotic Dis. 2014, 14, 486-495. [CrossRef] [PubMed]

7. Raghavan, R.K.; Goodin, D.G.; Neises, D.; Anderson, G.A.; Ganta, R.R. Hierarchical Bayesian spatio-temporal analysis of climatic and socio-economic determinants of Rocky Mountain spotted fever. PLoS ONE 2016, 11, e0150180. [CrossRef]

8. Hanzlicek, G.A.; Raghavan, R.K.; Ganta, R.R.; Anderson, G.A. Bayesian space-time patterns and climatic determinants of bovine anaplasmosis. PLoS ONE 2016, 11, e0151924. [CrossRef] [PubMed]

9. Savage, H.M.; Godsey, M.S., Jr.; Tatman, J.; Burkhalter, K.L.; Hamm, A.; Panella, N.A.; Ghosh, A.; Raghavan, R.K. Surveillance for Heartland and Bourbon viruses in eastern Kansas, June 2016. J. Med. Entomol. 2018, 55, 1613-1616. [CrossRef]

10. Savage, H.M.; Godsey, M.S., Jr.; Panella, N.A.; Burkhalter, K.L.; Manford, J.; Trevino-Garrison, I.C.; Straily, A.; Wilson, S.; Bowen, J.; Raghavan, R.K. Surveillance for tick-borne viruses near the location of a fatal human case of Bourbon virus (Family Orthomyxoviridae: Genus Thogotovirus) in eastern Kansas, 2015. J. Med. Entomol. 2018, 55, 701-705. [CrossRef]

11. Raghavan, R.K.; Goodin, D.G.; Dryden, M.W.; Hroobi, A.; Gordon, D.M.; Cheng, C.; Nair, A.D.; Jakkula, L.U.; Hanzlicek, G.A.; Anderson, G.A.; et al. Heterogeneous associations of ecological attributes with tick-borne Rickettsial pathogens in a periurban landscape. Vector Borne Zoonotic Dis. 2016, 16, 569-576. [CrossRef]

12. Halos, L.; Bord, S.; Cotté, V.; Gasqui, P.; Abrial, D.; Barnouin, J.; Boulouis, H.-J.; Vayssier-Taussat, M.; Vourc, G. Ecological factors characterizing the prevalence of bacterial tick-borne pathogens in Ixodes ricinus ticks in pastures and woodlands. Appl. Environ. Microbiol. 2010, 76, 4413-4420. [CrossRef] [PubMed]

13. Johnson, T.L.; Boegler, K.A.; Clark, R.J.; Delorey, M.J.; Bjork, J.K.H.; Dorr, F.M.; Schiffman, E.K.; Neitzel, D.F.; Monaghan, A.J.; Eisen, R.J. An acarological risk model predicting the density and distribution of host-seeking Ixodes scapularis nymphs in Minnesota. Am. J. Trop. Med. Hyg. 2018, 98, 1671-1682. [CrossRef] [PubMed]

14. Polito, V.J.; Baum, K.; Payton, M.E.; Little, S.E.; Fuhlendorf, S.D.; Reichard, M.V. Tick abundance and levels of infestation on cattle in response to patch burning. Rangel. Ecol. Manag. 2013, 66, 545-552. [CrossRef]

15. Gleim, E.R.; Zemtsova, G.E.; Berghaus, R.; Levin, M.L.; Conner, M.; Yabsley, M.J. Frequent prescribed fires can reduce risk of tick-borne diseases. Sci. Rep. 2019, 9, 1-10. [CrossRef]

16. Barnard, D.R. Aspects of the bovine host-lone star tick interaction process in forage areas. In Morphology, Physiology and Behavioral Ecology of Ticks; Sauer, J.R., Hair, J.A., Eds.; Horwood: Chichester, UK, 1986; pp. 428-444.

17. Hair, J.A.; Bowman, J. Behavioral ecology of Amblyomma americanum (L.). In Morphology, Physiology and Behavioral Ecology of Ticks; Sauer, J.R., Hair, J.A., Eds.; Horwood: Chichester, UK, 1986; pp. 406-427.

18. White, S.C.; Mock, D.E. Ixodes scapularis (Acari: Ixodidae) in Kansas: A new distribution record. J. Med. Èntomol. 1991, 28, 872-873. [CrossRef] [PubMed]

19. Kollars, T.M.; Oliver, J.H.; Kollars, P.G.; Durden, L.A. Seasonal activity and host associations of Ixodes scapularis (Acari: Ixodidae) in southeastern Missouri. J. Med. Èntomol. 1999, 36, 720-726. [CrossRef] [PubMed]

20. Hroobi, A.; Boorgula, G.D.; Gordon, D.; Bai, J.; Goodin, D.; Anderson, G.; Wilson, S.; Staggs, A.; Raghavan, R.K. Diversity and seasonality of host-seeking ticks in a periurban environment in the central Midwest (USA). PLoS ONE 2021, 16, e0250272. [CrossRef] [PubMed]

21. Remesar, S.; Fernández, P.D.; Venzal, J.M.; Pérez-Creo, A.; Prieto, A.; Estrada-Peña, A.; López, C.M.; Panadero, R.; Fernández, G.; Díez-Baños, P.; et al. Tick species diversity and population dynamics of Ixodes ricinus in Galicia (north-western Spain). Ticks Tick Borne Dis. 2018, 10, 132-137. [CrossRef]

22. Schulze, T.L.; Jordan, R.A.; Hung, R.W. Effects of selected meteorological factors on diurnal questing of Ixodes scapularis and Amblyomma americanum (Acari: Ixodidae). J. Med. Èntomol. 2001, 38, 318-324. [CrossRef] [PubMed] 
23. Harlan, H.J.; Foster, W.A. Micrometeorologic factors affecting field host-seeking activity of adult Dermacentor variabilis (Acari: Ixodidae). J. Med. Èntomol. 1990, 27, 471-479. [CrossRef]

24. Sonenshine, D.E.; Haines, G. A convenient method for controlling populations of the american dog tick, Dermacentor variabilis (Acari: Ixodidae) in the natural environment. J. Med. Ėntomol. 1985, 22, 577-583. [CrossRef] [PubMed]

25. Haile, D.G.; Mount, G.A. Computer simulation of population dynamics of the lone star tick, Amblyomma americanum (Acari: Ixodidae). J. Med. Èntomol. 1987, 24, 356-369. [CrossRef]

26. Yoder, J.A.; Rosendale, A.J.; Benoit, J.B. Short day-triggered quiescence promotes water conservation in the American dog tick, Dermacentor variabilis. J. Comp. Physiol. B 2015, 186, 287-296. [CrossRef]

27. Yoder, J.A.; Hedges, B.Z.; Benoit, J.B. Water balance of the American dog tick, Dermacentor variabilis, throughout its development with comparative observations between field-collected and laboratory-reared ticks. Int. J. Acarol. 2012, 38, 334-343. [CrossRef]

28. Campbell, A.; Harris, D.L. Reproduction of the American dog tick, Dermacentor variabilis, under laboratory and field conditions. Environ. Ėntomol. 1979, 8, 734-739. [CrossRef]

29. Civitello, D.J.; Flory, S.L.; Clay, K. Exotic grass invasion reduces survival of Amblyomma americanum and Dermacentor variabilis ticks (Acari: Ixodidae). J. Med. Èntomol. 2008, 45, 867-872. [CrossRef] [PubMed]

30. Raghavan, R.K.; Peterson, A.T.; Cobos, M.E.; Ganta, R.; Foley, D. Current and future distribution of the lone star tick, Amblyomma americanum (L.) (Acari: Ixodidae) in north America. PLoS ONE 2019, 14, e0209082. [CrossRef] [PubMed]

31. Boorgula, G.D.Y.; Peterson, A.T.; Foley, D.H.; Ganta, R.R.; Raghavan, R.K. Assessing the current and future potential geographic distribution of the American dog tick, Dermacentor variabilis (Say) (Acari: Ixodidae) in north America. PLoS ONE 2020, 15, e0237191. [CrossRef] [PubMed]

32. Raghavan, R.K.; Barker, S.; Cobos, M.E.; Barker, D.; Teo, E.J.M.; Foley, D.H.; Nakao, R.; Lawrence, K.; Heath, A.C.G.; Peterson, A.T. Potential spatial distribution of the newly introduced long-horned tick, Haemaphysalis longicornis in north America. Sci. Rep. 2019, 9,1-8. [CrossRef]

33. Randolph, S.E.; Storey, K. Impact of microclimate on immature tick-rodent host interactions (Acari: Ixodidae): Implications for parasite transmission. J. Med. Èntomol. 1999, 36, 741-748. [CrossRef]

34. Smith, C.N.; Cole, M.M. Effect of length of day on the activity and hibernation of the American dog tick, Dermacentor variabilis (Say) (Acarina: Ixodidae). Ann. Èntomol. Soc. Am. 1941, 34, 426-431. [CrossRef]

35. Childs, J.E.; Paddock, C.D. The ascendancy of Amblyomma americanum as a vector of pathogens affecting humans in the United States. Annu. Rev. Entomol. 2003, 48, 307-337. [CrossRef]

36. Savage, H.M.; Godsey, M.S.G., Jr.; Lambert, A.; Panella, N.A.; Burkhalter, K.L.; Harmon, J.R.; Lash, R.R.; Ashley, D.C.; Nicholson, W.L. First detection of Heartland virus (Bunyaviridae: Phlebovirus) from field collected arthropods. Am. J. Trop. Med. Hyg. 2013, 89, 445-452. [CrossRef] [PubMed]

37. Raghavan, R.K.; Goodin, D.G.; Hanzlicek, G.A.; Zolnerowich, G.; Dryden, M.W.; Anderson, G.A.; Ganta, R.R. Maximum entropy-based ecological niche model and bio-climatic determinants of lone star tick (Amblyomma americanum) niche. Vector Borne Zoonotic Dis. 2016, 16, 205-211. [CrossRef] [PubMed]

38. Bishopp, F.C.; Trembley, H.L. Distribution and hosts of certain north American ticks. J. Parasitol. 1945, 31. [CrossRef]

39. Tugwell, P.; Lancaster, J.L., Jr. Notes on the seasonal occurrence of six tick species in northwest Arkansas. J. Kans. Entomol. Soc. 1963, 36, 167-171.

40. Kocan, K.M.; Hair, J.A.; Ewing, S.A. Ultrastructure of Anaplasma marginale Theiler in Dermacentor andersoni stiles and Dermacentor variabilis (Say). Am. J. Vet. Res. 1980, 41, 1966-1976. [PubMed]

41. Logan, T.M.; Kocan, K.M.; Edwards, W.; Hair, J.A.; Claypool, P.L.; Ewing, S.A. Persistence of colonies of Anaplasma marginale in overwintering Dermacentor variabilis. Am. J. Vet. Res. 1987, 48.

42. Stich, R.; Kocan, K.M.; Palmer, G.H.; Ewing, S.A.; Hair, J.A.; Barron, S.J. Transstadial and attempted transovarial transmission of Anaplasma marginale by Dermacentor variabilis. Am. J. Vet. Res. 1989, 50, 1377-1380.

43. Coley, K. Identification guide to larval stages of ticks of medical importance in the USA. University Honors. Program Thesis, Georgia Southern University, Statesboro, GA, USA, 2015.

44. Stich, R.W.; Blagburn, B.L.; Bowman, D.D.; Carpenter, C.; Cortinas, M.R.; Ewing, S.A.; Foley, D.; Foley, J.E.; Gaff, H.; Hickling, G.J.; et al. Quantitative factors proposed to influence the prevalence of canine tick-borne disease agents in the United States. Parasites Vectors 2014, 7, 1-8. [CrossRef] [PubMed]

45. Knudson, C. An Introduction to Model-Fitting with the R Package GLMM. Available online: https://mran.microsoft.com/ snapshot/2015-04-08/web/packages/glmm/vignettes/intro.pdf (accessed on 6 August 2021).

46. R Core Team. R: A Language and Environment for Statistical Computing; R Foundation for Statistical Computing: Vienna, Austria, 2018; Available online: https:/ / www.R-project.org/ (accessed on 6 August 2021). 